University of Nebraska - Lincoln

DigitalCommons@University of Nebraska - Lincoln

USDA National Wildlife Research Center - Staff Publications
U.S. Department of Agriculture: Animal and Plant Health Inspection Service

2014

\title{
Seven-year responses of trees to experimental hurricane effects in a tropical rainforest, Puerto Rico
}

\author{
Jess K. Zimmerman \\ University of Puerto Rico - Rio Piedras Campus \\ James Aaron Hogan \\ University of Puerto Rico - Rio Piedras Campus \\ Aaron B. Shiels \\ University of Puerto Rico - Rio Piedras Campus, aaron.b.shiels@aphis.usda.gov \\ John E. Bithorn \\ University of Puerto Rico - Rio Piedras Campus \\ Samuel Matta Carmona \\ University of Puerto Rico - Rio Piedras Campus
}

See next page for additional authors

Follow this and additional works at: https://digitalcommons.unl.edu/icwdm_usdanwrc

Part of the Life Sciences Commons

Zimmerman, Jess K.; Hogan, James Aaron; Shiels, Aaron B.; Bithorn, John E.; Carmona, Samuel Matta; and Brokaw, Nicholas, "Seven-year responses of trees to experimental hurricane effects in a tropical rainforest, Puerto Rico" (2014). USDA National Wildlife Research Center - Staff Publications. 1725.

https://digitalcommons.unl.edu/icwdm_usdanwrc/1725

This Article is brought to you for free and open access by the U.S. Department of Agriculture: Animal and Plant Health Inspection Service at DigitalCommons@University of Nebraska - Lincoln. It has been accepted for inclusion in USDA National Wildlife Research Center - Staff Publications by an authorized administrator of DigitalCommons@University of Nebraska - Lincoln. 


\section{Authors}

Jess K. Zimmerman, James Aaron Hogan, Aaron B. Shiels, John E. Bithorn, Samuel Matta Carmona, and Nicholas Brokaw 


\title{
Seven-year responses of trees to experimental hurricane effects in a tropical rainforest, Puerto Rico
}

\author{
Jess K. Zimmerman *, James Aaron Hogan, Aaron B. Shiels ${ }^{1}$, John E. Bithorn, Samuel Matta Carmona, \\ Nicholas Brokaw
}

Department of Environmental Science, University of Puerto Rico, Rio Piedras Campus, P.O. Box 70337, Rio Piedras, PR 00936-8377, USA

\section{A R T I C L E I N F O}

Article history:

Available online 16 April 2014

\section{Keywords:}

Basal area

Intermediate Disturbance Hypothesis

Luquillo Experimental Forest

Mortality

Recruitment

Species diversity

\begin{abstract}
A B S T R A C T
We experimentally manipulated key components of severe hurricane disturbance, canopy openness and detritus deposition, to determine the independent and interactive effects of these components on tree recruitment, forest structure, and diversity in a wet tropical forest in the Luquillo Experimental Forest, Puerto Rico. Canopy openness was increased by trimming branches, and we manipulated debris by adding or subtracting the trimmed materials to the trimming treatments, in a $2 \times 2$ factorial design replicated in three blocks. Tree (stems $\geqslant 1 \mathrm{~cm}$ diameter at breast height) responses were measured during the 9-year study, which included at least 1 year of pre-manipulation monitoring. When the canopy was trimmed, stem densities increased $>2$-fold and rates of recruitment increased $>25$-fold. Deposition of canopy debris did not markedly affect stem densities but did have small yet significant effects on tree basal area. Basal area increased about $10 \%$ when debris was added to plots with intact canopies; the other treatments exhibited smaller or no increases in basal area over time. Much of the dynamics of stem densities were due to changes in the smallest size class (1-2.5 cm diameter), which responded with a pulse of recruitment in the canopy trimmed treatments, and a steady loss in plots with intact canopies. The decreases in stem densities in the plots with intact canopies is attributed to observed on-going forest thinning from the last natural severe hurricane disturbance in 1998. Given these repeated hurricane effects, our study enabled an experimental test of the Intermediate Disturbance Hypothesis (IDH), for which we predicted an increase in species diversity in canopy trimmed treatments and a loss of species in the treatments with intact canopies. Measured patterns of diversity gave partial support to the predictions of IDH, although raw species richness of sampled plots fit the predictions better than richness adjusted for differences in stem densities among treatments. Ordination of species responses in the community identified a guild of pioneer species responding to the trimmed treatments, but not the debris additions, amongst substantial background variation in species composition unrelated to the experimental treatments. These results are consistent with a growing consensus that, while trade-offs of resilience and resistance govern many species responses to hurricane disturbance, other environmental and historical factors are equally or more important in governing community dynamics in hurricane-disturbed forests.
\end{abstract}

(c) 2014 Published by Elsevier B.V.

\section{Introduction}

Wind storms are a dominant component of the disturbance regime of forested ecosystems in many parts of the world (Everham and Brokaw, 1996; Whitmore and Burslem, 1998; Lugo, 2008). Many past studies describe the impacts of tropical cyclones

\footnotetext{
* Corresponding author. Tel.: +1 787 764-0000x2867.

E-mail address: jesskz@ites.upr.edu (J.K. Zimmerman).

1 Present address: USDA, National Wildlife Research Center, Hawaii Field Station, P.O. Box 10880, Hilo, HI 96721, USA.
}

on regional forests (Walker et al., 1991, 1996; Stone and Finkl, 1995; Burslem and Whitmore, 1999; Turton, 2008; Webb et al., 2014), and those in the Caribbean emphasize the resilience of forests to even the most severe hurricanes (Scatena et al., 1996; Vandermeer et al. 2000; Tanner and Bellingham, 2006; Imbert and Portecop, 2008; McGroddy et al., 2013). While such rapid tree recovery is largely a result of species adaptations to severe wind disturbance (Zimmerman et al., 1994; Bellingham et al., 1995; Brokaw et al., 2004), a mechanistic understanding of the tree responses during the first decade following hurricane disturbance is lacking. This can be determined by experimental manipulations similar to those conducted at Harvard Forest in the north-eastern 
USA (Carlton and Bazzaz, 1998; Cooper-Ellis et al., 1999; Barker Plotkin et al., 2013) and the Canopy Trimming Experiment (CTE) in the Luquillo Experimental Forest, Puerto Rico (Richardson et al., 2010; Shiels et al., 2010; Shiels and González, 2014).

The CTE was designed to separate two critical effects normally confounded in a hurricane - increased canopy openness and the deposition of debris on the forest floor (Shiels and González, 2014). Earlier, Shiels et al. (2010) reported on the initial responses of woody vegetation in the CTE, focusing on the dynamics of the seedling layer. The deposition of debris killed many existing woody seedlings and provided a mechanical barrier that suppressed seedling recruitment, but these effects were largely transient. The increase in understory light availability caused by canopy trimming appeared more important than the impacts of hurricane debris, stimulating increased seedling recruitment and density of pioneer species (e.g., Cecropia schreberiana) known to respond strongly to canopy opening caused by hurricanes (Zimmerman et al., 2010). This effect was apparent through the end of the study, four years after the implementation of treatments (Shiels et al., 2010).

While Shiels et al. (2010) were able to establish the impacts of canopy opening on tree sapling recruitment, their observations were not of sufficient length to clearly determine the full impacts of canopy openness on the existing trees. Patterns of mortality suggested little impact of canopy trimming, but these impacts may become more apparent as time proceeds (Walker, 1995). Also, while there was a small apparent increase in basal area caused by debris deposition (Shiels et al., 2010), suggesting a beneficial effect of debris on tree growth, this only became apparent at the end of the study. In addition, even though Shiels et al. (2010) showed that the trimming treatments influenced the tree community by causing recruitment of key pioneer species, they did not determine the impact of the treatments in the CTE on patterns of species diversity. Furthermore, a longer post-treatment observation period offers the opportunity to investigate species responses to the experimental treatments in more detail in view of the decadal impacts that a single hurricane can have on community dynamics (Crow, 1980; Lugo et al., 2000).

One relevant theory describing the diversity response of tree communities to wind disturbance is the Intermediate Disturbance Hypothesis (Connell, 1978; Doyle, 1981; Sheil and Burslem, 2004). The theory assumes trade-offs either in species competitive abilities or niche partitioning whereby more recently disturbed forest patches serve as opportunities for the establishment of rapidly growing, shade intolerant guild of pioneer species that persist in a community dominated by slower-growing species tolerant of low resource conditions (Pacala and Rees, 1998; Uriarte et al., 2012). To the degree that the presence of two (or more) generalized species groups with different light requirements overlap in space and time (Miller et al., 2011), species diversity of local, recently disturbed forest patches will reach a maximum before declining, as shade tolerant species come to dominate the patch. While the validity of the theory is still debated on both empirical and theoretical grounds (Bongers et al. 2009; Fox, 2013; Sheil and Burslem, 2004; 2013), Miller and his colleagues have given new life to IDH by strengthening its theoretical underpinnings (Miller and Chesson, 2009; Miller et al., 2011). We take advantage of previous severe hurricane disturbance at our site to frame our test of IDH (Zimmerman et al., 1994; 2010). Since no severe hurricanes affected our study once it started, we can effectively compare the more recent experimental canopy opening to that caused by a hurricane 14 years in advance of the start of our observations.

Shiels et al. (2010) showed that an initial response by species to canopy trimming was increased recruitment of two common pioneer species, Cecropia schreberiana and Psychotria berteroana with no species responding to debris deposition detected at the time of the study. Again, with a greater time span of observations, it is possible to further detail species responses to the experimental manipulations. In particular, we wish to investigate the generality of our previous observations by utilizing ordination methods to illuminate the responses of all species in the forest community, not just the most common species as was analyzed by Shiels et al. (2010). This approach would support the goal of understanding diversity responses to the manipulations in the context of trade-offs in species resistance and resilience to hurricane disturbance (Boucher et al., 1994; Zimmerman et al., 1994; Burslem and Whitmore, 1999; Tanner and Bellingham, 2006; Uriarte et al., 2012).

Therefore, we revisit the response of woody vegetation to treatments in the CTE (Shiels et al., 2010), addressing the following questions:

(1) What are the long-term mortality and growth rates of saplings (woody plants $\geqslant 1 \mathrm{~cm}$ DBH) recruited into the CTE treatments where the canopy was trimmed and how does this relate to forest dynamics in forest naturally disturbed by hurricanes?

(2) How does the deposition of debris generated by trimming the forest canopy influence forest dynamics, particularly long-term patterns of tree growth and mortality? Moreover, is there a positive effect of debris deposition and does this effect interact with the trimming treatments?

(3) To what degree do patterns of changes in species diversity in the CTE support or refute patterns predicted by IDH?

(4) How does species composition respond to the experimental treatments and how does this enhance our understanding of community dynamics in hurricane-disturbed forests.

\section{Materials and methods}

\subsection{Study site}

This study took place in the Luquillo Experimental Forest (LEF) in north-eastern Puerto Rico, near the El Verde Field Station (EVFS; $18^{\circ} 20^{\prime} \mathrm{N}, 65^{\circ} 49^{\prime} \mathrm{W}$ ), where annual rainfall averages $3500 \mathrm{~mm}$ (Zimmerman et al., 2007), elevation is $340-485 \mathrm{~m}$ a.s.l., and the terrain is steep ( $24 \%$ average slope) and rocky ( $25 \%$ of the soil surface covered by boulders; Soil Survey Staff, 1995; Shiels et al., 2010). The study site is in tabonuco forest (subtropical wet forest in the Holdridge System; Ewel and Whitmore, 1973), which is the lowermost and dominant of four general vegetation zones along an altitudinal gradient across the LEF. The prominent tree species at the site include Sloanea berteroana (Elaeocarpaceae), Dacryodes excelsa (Burseraceae), Prestoea acuminata var. montana (Arecaceae), and Manilkara bidentata (Sapotaceae). Before our study, the two most recent severe hurricanes passing over our site included Hurricane Hugo (a category 4 storm on the Saffir-Simpson hurricane scale) in September 1989, and Hurricane Georges (a category 3 storm) in September 1998. No storms of hurricane strength impacted the site during our study and there were not significant droughts (Shiels and González, 2014).

\subsection{Experimental design}

Three blocks were established in tabonuco forest of similar age and land-use history (>80\% cover in 1936; Foster et al., 1999; Thompson et al., 2002) and topography. The three blocks were located in an area of approximately 50 ha near EVFS at similar elevations (340-485 $\mathrm{m}$ a.s.l.). Individual plot size was $30 \times 30 \mathrm{~m}$, selected to reflect the average size of damaged patches of canopy that were observed following Hurricanes Hugo and Georges (Brokaw and Grear, 1991; Zimmerman et al., 2010). Plots were 
spaced at least $20 \mathrm{~m}$ apart within each block (see map of plot layout in Shiels and González, 2014).

To minimize edge effects within each $30 \times 30 \mathrm{~m}$ treatment plot, the core $20 \times 20$ interior area was used for measurement. This interior measurement area was divided into 16 quadrats with adjacent walking trails to minimize observer impacts. A 1.5 year monitoring period began in 2003 to establish baseline measurements, prior to applying treatments.

Within each block, plots were randomly assigned one of the four treatments: (1) Trim + debris, where the canopy was trimmed and the detritus (debris) was left on the forest floor; (2) Trim + no debris, where the canopy was trimmed and the debris from the trimming was added to another plot in a block to create the (3) No trim + debris treatment; and (4) Control (No trim + no debris), where neither the canopy was cut nor the forest floor debris changed. Treatments were applied to each block individually by certified arborists from November 2004 to June 2005. The extent of the canopy trimming area was extended from the plot boundaries vertically to include all woody-stemmed projections, and trees were trimmed using the following criteria: All non-palm trees $\geqslant 15 \mathrm{~cm}$ diameter at $1.3 \mathrm{~m}$ height (DBH) had their branches that were less than $10 \mathrm{~cm}$ diameter removed. For non-palm trees between 10 and $15 \mathrm{~cm}$ DBH, each tree was trimmed at $3 \mathrm{~m}$ height. For all palm trees $\geqslant 3 \mathrm{~m}$ tall, all palm fronds were trimmed at the connection with the main stem, making sure to preserve the apical meristem. No vegetation was trimmed below $3 \mathrm{~m}$ height, except in cases where trimmed palms had fronds below $3 \mathrm{~m}$ height. These levels of trimming increased canopy openness to $\sim 16 \%$ (Shiels et al., 2010; Shiels and González, 2014), a level perhaps less than that caused by a natural hurricane of high severity because the forest matrix surrounding each plot was unaffected (see Shiels et al., 2010 for detailed discussion).

The resulting canopy debris was divided into three categories: wood (branches $\geqslant 1.5 \mathrm{~cm}$ diameter), leaves and twigs (branches $<1.5 \mathrm{~cm}$ diameter and all non-palm foliage), and palm fronds. The debris was immediately weighed to establish wet mass, and then samples of debris were weighed after being dried at $45^{\circ} \mathrm{C}$ until constant mass was achieved to develop wet-dry mass ratios. All debris was sorted and distributed evenly to the two debris plots within each block. On average $11,157 \pm 362 \mathrm{~kg}$ of (wet mass; $12.4 \pm 0.4 \mathrm{~kg} \mathrm{~m}^{-2}$ ) debris $(6530 \pm 186 \mathrm{~kg}$ dry mass; $7.3 \pm 0.2 \mathrm{~kg} \mathrm{~m}^{-2}$ ) was removed from each trim plot. Following some loss due to decomposition, on average $6 \mathrm{~kg} \mathrm{~m}^{-2}$ was placed either in the plot it was trimmed from or in a No trim plot in the same block. Nevertheless, these amounts of debris deposition were remarkably similar to those observed at the site in Hurricane Hugo in 1989 (Lodge et al., 1991; Shiels et al., 2010).

These manipulations do not include the impact of stem breakage or uprooting, which, while important to our forests, affect a relatively small area relative to the primary effects of canopy opening and debris deposition (Zimmerman et al., 1994; Shiels et al., 2010).

\subsection{Plant measurements}

All woody plants $\geqslant 1 \mathrm{~cm} \mathrm{DBH}$, including trees, shrubs and lianas, hereafter termed stems, were measured in each plot on the starting dates of March 1, 2003; October 15, 2004; September 17, 2007; October 17, 2008; November 12, 2009; February 7, 2011; and February 6,2012 . At the installation of the plots, all stems were tagged, identified to species (nomenclature follows Axelrod, 2011) and mapped for relocation. The pre-treatment measurement period took place in March 2003 and October 2004 and the post-treatment measures took place in September 2007 and thereafter. The measurement of stems for each sampling took on average 17 days.

Lumber crayons were used to mark the points of measurement in order to minimize sampling error between subsequent measure- ments. Stems with DBH $<5 \mathrm{~cm}$ were measured using vernier calipers with a precision of a hundredth of a centimeter $(0.01 \mathrm{~cm})$; stems with diameters $>5 \mathrm{~cm}$ were measured using metric diameter tape measures with a precision of up to $0.1 \mathrm{~cm}$. Standing main stems and their sprouts were associated in the data for later use in the growth and mortality analyses and basal area calculations. In the classification 'stems' we include all palms in which the attachment point of the youngest leaves reached a height of $1.3 \mathrm{~m}$ or higher, measuring the diameter between the two leaf scars closest to $1.3 \mathrm{~m}$ height. Stem measurement methods follow the Center for Tropical Forest Science (CTFS) protocol (Condit, 1998).

\subsection{Data analysis}

Stems densities and basal area were expressed on a per ha basis. Rates of mortality and recruitment were calculated as described by Shiels et al. (2010): mortality rate $=\left(\ln N_{t}-\ln \left(N_{t}-\# \operatorname{dead} d_{t+1}\right)\right) /$ \#months, and recruitment rate $=\left(\ln \left(N_{t}+\#\right.\right.$ recruits $\left.\left._{t+1}\right)-\ln N_{t}\right) /$ \#months, where $N_{t}$ is the number of seedlings or stems alive at the beginning of a time interval $(t)$. Stem recruitment occurred when individuals $<1 \mathrm{~cm}$ DBH grew to sizes $\geqslant 1 \mathrm{~cm}$ DBH.

To investigate variation in size distributions over time, stems were grouped into the following DBH size categories: $1-2.49 \mathrm{~cm}$; $2.5-4.99 \mathrm{~cm} ; 5-9.99 \mathrm{~cm} ; 10-14.99 \mathrm{~cm} ; 15-19.99 \mathrm{~cm}$; and $>20 \mathrm{~cm}$. Species diversity was calculated in two ways; (1) species density $(S)$ was calculated by determining the number of species present in each $20 \times 20$ measurement plot; (2) rarefaction was used to estimate tree diversity independent of changes in stem density (Gotelli and Colwell, 2001). For the latter, rarefaction curves were implemented in R (R Development Core Team, 2013) using the Vegan package (Oksanen et al., 2013) estimates of species richness in a sample of 50 stems $\left(S_{n=50}\right)$. This sample size was chosen as an approximate maximum value of stem density that could be used to compare amongst all plots and sampling times (Molino and Sabatier, 2001). Tree responses to experimental treatments over time were analyzed using repeated measures analysis of variance (ANOVA) in the ez package for analysis and visualization of factorial experiments (Lawrence, 2013) in R.

Variation in species composition among blocks and treatments (plots) over time ( $n=84$ sample units) was compared using Nonmetric Multidimensional Scaling (NMS; Clarke, 1993; McCune and Grace, 2002) using PC-ORD (McCune and Medford, 2011). We adjusted each species' $(n=80)$ abundance relative to its maximum to give equal weight to all species (McCune and Grace, 2002). This was appropriate in this case because we are interested in how each species contributes to species richness patterns. The NMS was conducted using the Sorenson (or Bray-Curtis) distance matrix, which takes into account both species occurrences and their relative abundances when comparing sample units. NMS searches iteratively for the best set of rankings of the distances in the matrix that distinguishes among sample units using the fewest possible ordination axes. This was done in PC-ORD using the "slow and thorough" setting in Autopilot mode (McCune and Medford, 2011), which arrives at the best solution and number of axes based on several parameters of success (see McCune and Grace, 2002 for details). Once a solution was selected, final stress, a measure of the degree to which the ordination captures underlying variation in community composition through time, was calculated. We then determined the percent of variance in the original distance matrix that was explained by each axis of the ordination. Each of the resulting ordination axes in NMS are orthogonal to one another (McCune and Grace, 2002), therefore, we subjected values for each axis to a separate repeated measures ANOVA as described above to determine the effects of treatments and time. 


\section{Results}

\subsection{Forest structure}

Mean stem densities (all diameter classes) ranged from 3000 to 4200 per ha among treatments during the pre-manipulation period, 2003-2004 (Fig. 1A). Differences among treatments were apparent during this period, with the No trim + no debris and Trim + debris treatments exhibiting higher average densities than the remaining treatments. Circa 2.3 years after treatments were established, there were large (2000-4000 stems ha $\left.{ }^{-1}\right)$ increases in mean stem densities in the Trim treatments (Fig. 1A). Differences between the Trim and No trim treatments persisted until the end of the observation period in early 2012, although mean densities in the Trim treatments had declined to 4500 6000 stems ha ${ }^{-1}$ by then. There was a significant interaction between trimming and time (Table 1) indicating the large change in densities in the Trim treatments, but also due to the decline in stem densities in the No trim treatments (Fig. 1A). Debris addition significantly influenced overall stem density (Table 1) but did not result in significant differences over time (time $\times$ debris; Table 1 ), which would be expected if debris deposition influenced stem density after the pre-manipulation period. Thus, the observed differences were likely the result of pre-existing differences. Additionally, there was no significant interaction between trimming, debris additions, and time (Table 1 ).

Mean basal area (BA) showed a less dramatic response than did stem density to the treatment applications. There appeared to be a significant interaction between Trim and Debris treatments over time (Fig. 1B), but this interaction was not statistically significant, or even nearly so $(p=0.9904$; Table 1$)$. In general, mean BA increased significantly over time in all treatments (Table 1) and there was a significant interaction between debris addition and time resulting from a greater relative increase in BA in the Debris treatments over time. There was no significant interaction between trim treatments and time (Table 1). Closer inspection showed that the apparent decline in BA in Trim + no debris treatment plots beginning in late 2007 (Fig. 1B) was due to death of several large trees in a single plot resulting in a large loss in BA; the other two replicates exhibited small increases in BA during this same period. Thus, the overall trend in the Trim + no debris plots was one of little or no significant change over time, statistically indistinguishable from the trend in the Control (No trim + no debris) plots. In sum, these No debris treatments exhibited significantly less BA growth than treatments with debris added.

As expected from changes in mean stem density over time, mean recruitment rates increased strongly by 2007 in the Trim treatments (Fig. 2A) and were significantly greater than recruitment rates in No trim plots following treatment application (trim $\mathrm{x}$ time; Table 2). During the 2007 census, the mean stem recruitment rate in Trim + debris treatment was double that of the Trim + no debris treatment and this pattern was statistically significant (time $\times$ trim $\times$ debris; Table 1 and Fig. 2A). By 2009 overall mean recruitment rates in the Trim treatments had fallen back to rates similar to the No trim plots. Mean recruitment rates were very low in the No trim treatments throughout the study.

Stem mortality appeared to increase in all treatments from 2004 to 2007 (Fig. 2B); time significantly influenced the mortality rate overall (Table 2). Beginning in 2009, mortality rates in the Trim plots strongly exceeded those in the No trim plots, and these differences persisted until the end of the study in early 2012 (time $\times$ trim; Table 1 ). Stem mortality rates appeared to peak in 2010. The addition of debris had no significant impact on this pattern (Time $\times$ Trim $\times$ Debris; Table 1 ).

Because mortality patterns probably resulted from the loss of newly recruited stems over time and because of an interest in understanding the impact of trimming on the long-term mortality of trees in the size class that were trimmed for the study (particularly in light of the large loss of trees in one plot noted above), we conducted an additional analysis of mortality on trees $\geqslant 10 \mathrm{~cm}$ DBH. Specifically, we selected trees $\geqslant 10 \mathrm{~cm}$ DBH from the 2004 measurements, just before treatment initiation, and followed their mortality through the remaining observations. There was no significant effect of treatments on large tree mortality over time, neither for the Trim $(p=0.6557)$ nor the Debris $(p=0.4477)$ treatments and mortality rate did not change over time $(p=0.0825)$; none of the interactions were significant $(p>0.2100)$. Thus, significant changes in mortality among treatments are due to mortality patterns in the smallest size classes.

At the start of the experiment in 2003, there were no apparent differences in size distributions among treatments (Fig. 3). Canopy trimming clearly caused an increase in the density of the smallest stem size class by 2007 and this size class remained high in abundance, even while declining with time, throughout the observation period. At this same time, the No trim treatments showed a slow but steady decline in the abundance of the two smallest stem size classes, while the larger size classes remained largely stable.
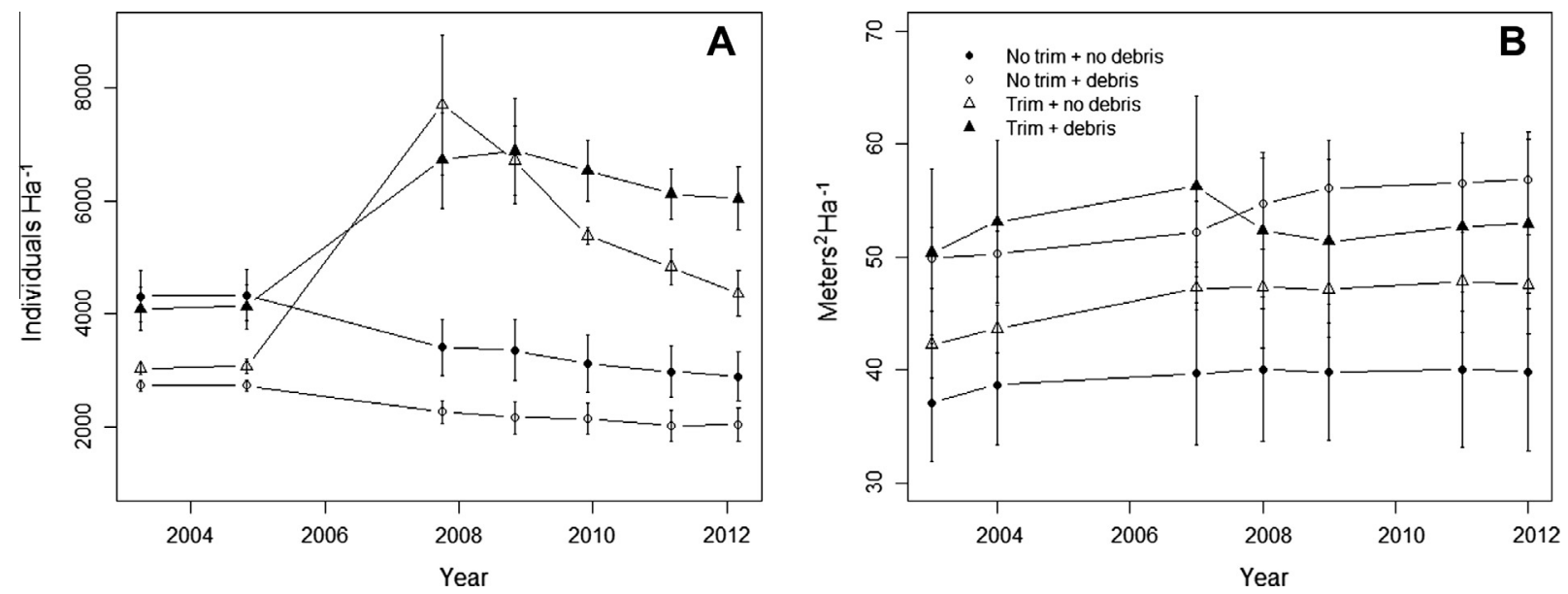

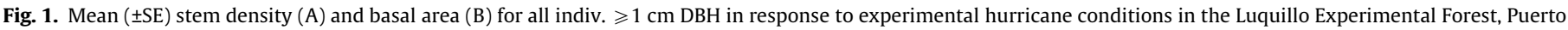
Rico. Canopy trimming and debris treatments occurred immediately after the 2004 census. $n=3$ for each treatment 
Table 1

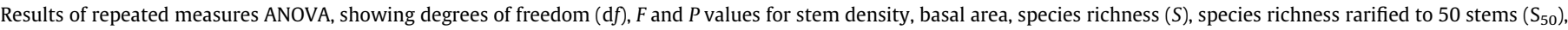
and Axes 1 through 3 derived from an ordination of species composition among treatments and time. $P$ values $<0.05$ are shown in bold.

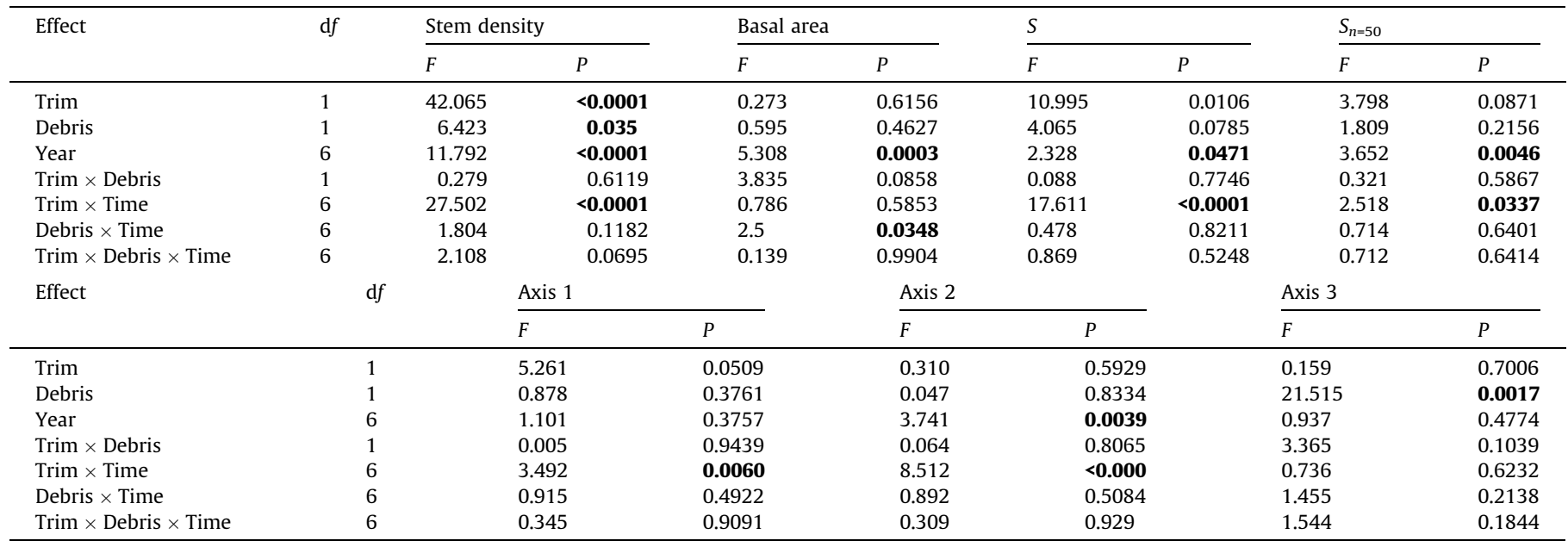
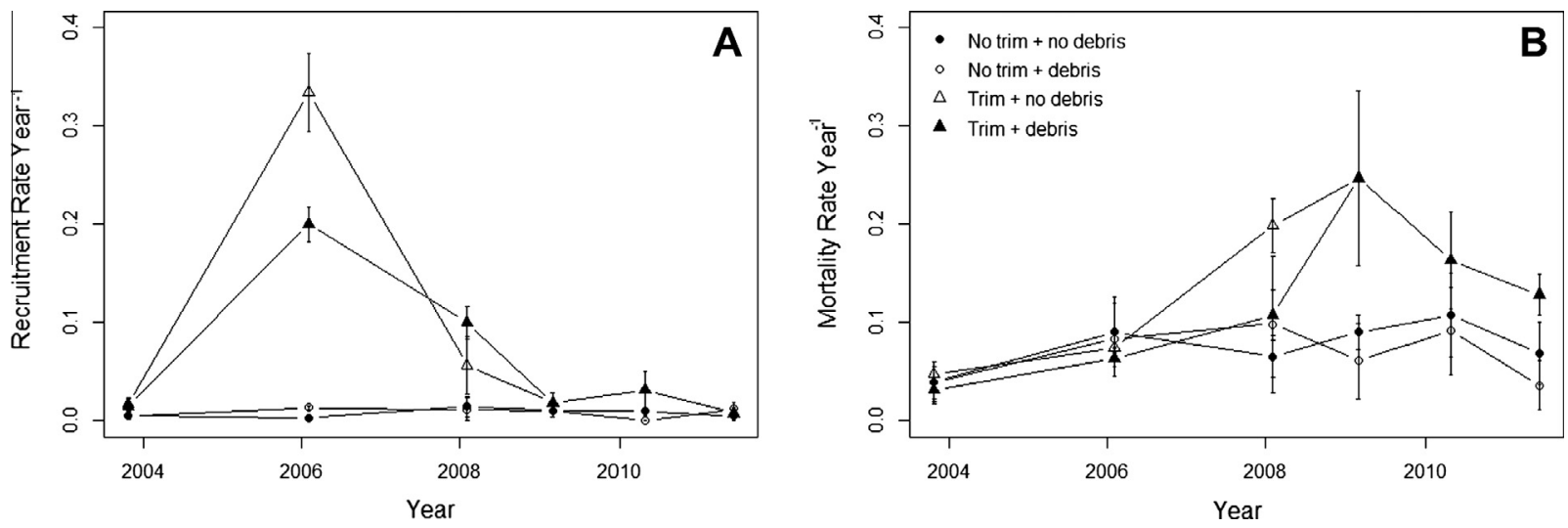

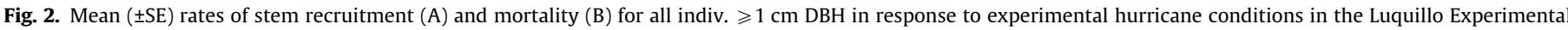
Forest, Puerto Rico. Canopy trimming and debris treatments occurred immediately after the 2004 census. $n=3$ for each treatment.

Table 2

Results of repeated measures ANOVA, showing $\mathrm{d} f, F$ and $P$ values for stem recruitment and mortality. $P$ values $<0.05$ are shown in bold.

\begin{tabular}{|c|c|c|c|c|c|}
\hline \multirow[t]{2}{*}{ Effect } & \multirow[t]{2}{*}{$\mathrm{d} f$} & \multicolumn{2}{|c|}{ Recruitment } & \multicolumn{2}{|c|}{ Mortality } \\
\hline & & $F$ & $P$ & $F$ & $P$ \\
\hline Trim & 1 & 169.474 & $<0.001$ & 2.060 & 0.1892 \\
\hline Debris & 1 & 0.725 & 0.4191 & 1.041 & 0.3375 \\
\hline Year & 5 & 44.646 & $<0.001$ & 7.352 & $<0.001$ \\
\hline Trim $\times$ Debris & 1 & 0.506 & 0.4972 & 1.835 & 0.2125 \\
\hline Trim $\times$ Time & 5 & 43.675 & $<0.001$ & 3.489 & 0.0104 \\
\hline Debris $\times$ Time & 5 & 5.581 & $<0.001$ & 0.837 & 0.5317 \\
\hline Trim $\times$ Debris $\times$ Time & 5 & 4.461 & $<0.001$ & 1.029 & 0.4136 \\
\hline
\end{tabular}

\subsection{Forest diversity}

We studied changes in species richness $(S)$ in two ways, using the species density per measurement plot (Fig. 4A) and by adjusting the number of species for differences in stem density per plot, adjusting $S$ to that expected in equal samples of 50 stems $\left(S_{50}\right.$; Fig. 4B). Analyses of diversity indices Shannon-Weiner and Simpson exhibited similar patterns to $S_{50}$ and were not presented. Pre-manipulation differences in the treatments were apparent, with the diversity of Trim + debris treatments appearing to exceed the other treatments (Fig. 4A and B). Species density produced more dramatic changes over time (Fig. $4 \mathrm{~A}$ ), and showed that $\mathrm{S}$ increased in Trim treatments by about 3-6 species over time while $S$ declined in the No trim treatments by roughly an equal amount. The three-way interaction of time, trimming, and debris for changes in $S$ was statistically significant (Table 1). Changes in $S_{50}$ were small, about 1-2 species per treatment, where there was any notable change (Fig. $4 \mathrm{~B}$ ). In general, $\mathrm{S}_{50}$ declined in the No trim treatments, and there was little change or an increase in the Trim treatments (time $\times$ trim; Table 1 ). The increase in $S_{50}$ in the Trim + no debris treatment was delayed in time compared to the pattern observed for $S$; the other patterns were similar between the two different richness measures. There was no significant effect of debris over time for $S_{50}$ nor was there a significant interaction between time, trimming, and debris (Table 1).

\subsection{Species composition}

The NMS ordination returned three axes with a final stress of 14.7, representing $69.4 \%$ of the variance in the original Sorenson distance matrix. This level of final stress is considered adequate for ecological studies (McCune and Grace, 2002) but suggests substantial residual variation not explained by the ordination. Axis 1 accounted for $30.8 \%$ of variance, while axes 2 and 3 accounted for $22.4 \%$ and $16.1 \%$, respectively, of the variance in the original matrix. A biplot of Axes 1 and 2, averaged over blocks and shown for each block separately (Fig. 5), showed the temporal changes 

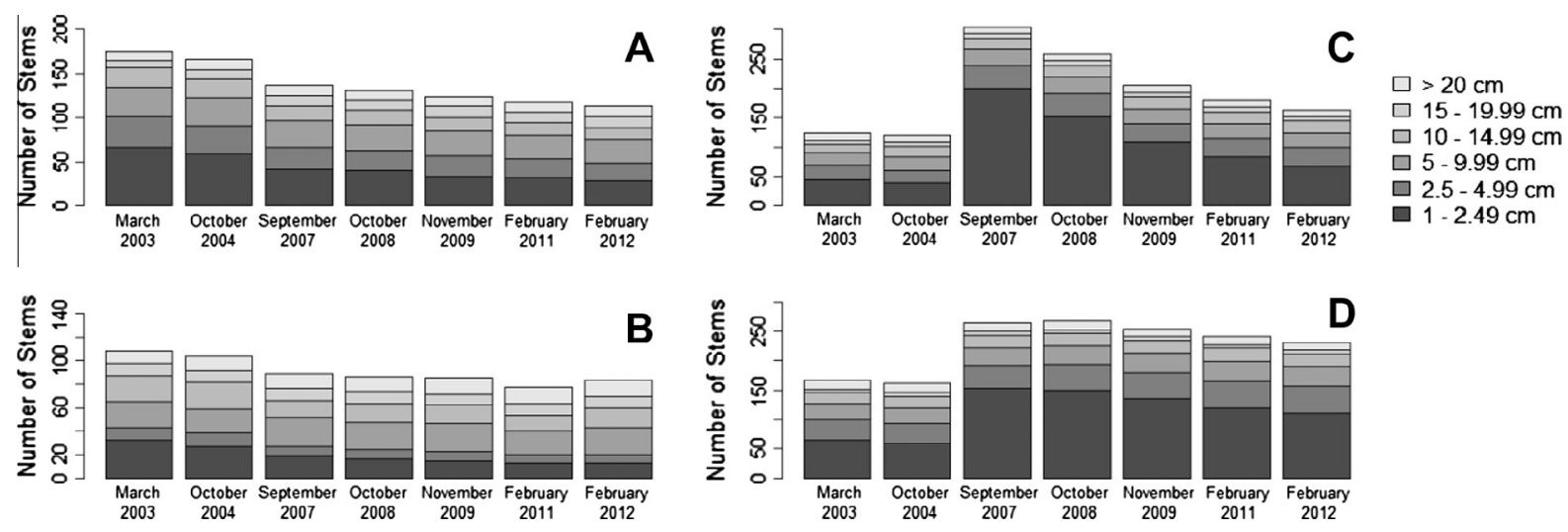

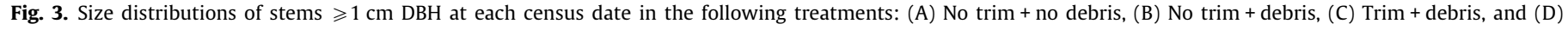
Trim + debris removed.
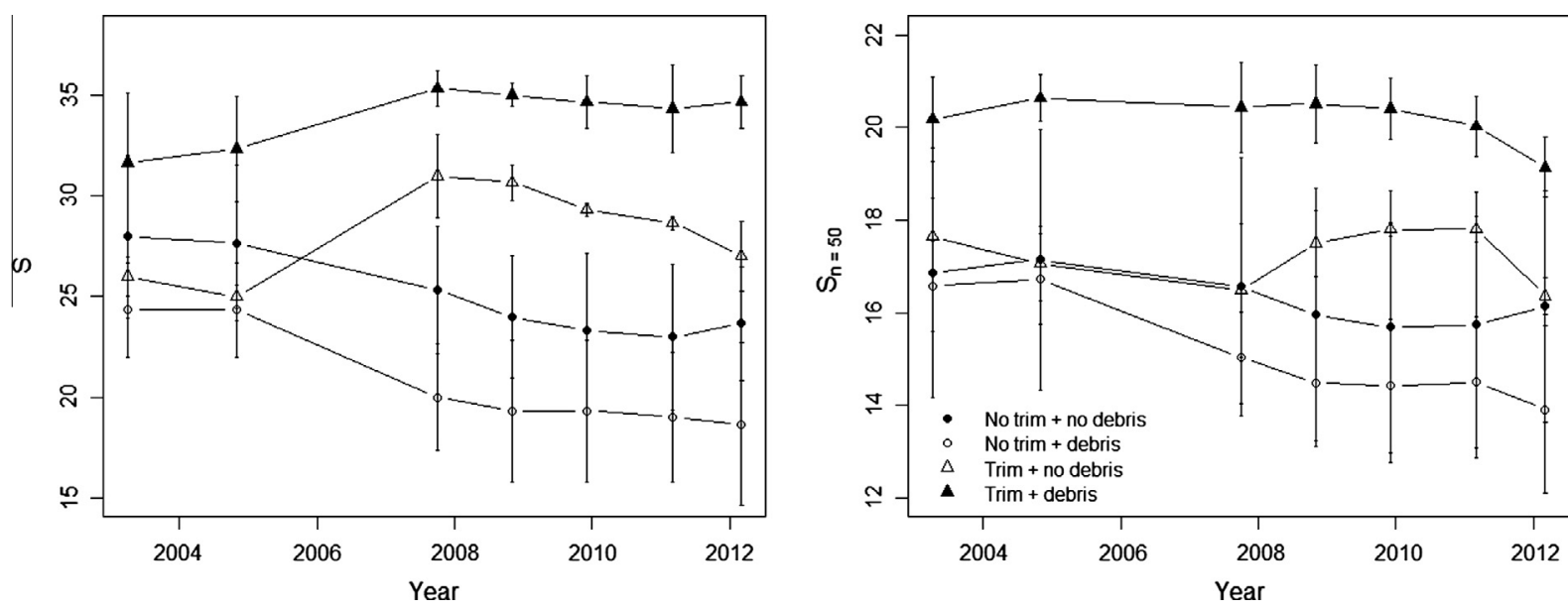

Fig. 4. Mean $( \pm S E)$ species density $(A)$ and species richness corrected for stem density (B). In $B$, species richness expected in a sample of 50 stems.

in species composition in the context of the substantial spatial variation in species composition. Addition of Axis 3 to these patterns (not shown) does not change the overall conclusions reported here and for simplicity, we proceed to describe patterns with Axis 1 and 2. Within treatments the average direction of change with time seemed to lie along a diagonal vector between Axis 1 and 2 . Changes over time appeared, on average, to be greatest in the two Trim treatments, though this pattern was not borne out in all sampled blocks (Fig. 6). Repeated measures ANOVA on each of the orthogonal axes (Table 1) indicated a significant (Axis 2) or marginally nonsignificant (Axis 1 ) effect of canopy trimming on species composition. Much of this effect we interpret as due to premanipulation differences in species composition due to patchy species distributions. For example, over 40 stems of Rheedia portoricensis (RHEPOR, Table 3 and Fig. 6) were found in a single plot in Block B of the Trim + no debris treatment with few found elsewhere. As the NMS placed RHEPOR on the far left side of species space, the averaged results for Trim + no debris are biased in this direction. Other similar differences in species dominance caused the Trim + no debris treatment lie to the left hand side of the biplot for each block, irrespective of time before or after the manipulations. Similarly, individuals of Cordia sulcata (CORSUL) occurred in two plots of No Trim + no debris and a single plot of No trim + debris. This and other pre-existing differences in these two treatments, unrelated to the manipulations, caused them to consistently fall to the right hand side of the NMS biplots (Fig. 6). Thus, some of the overall treatment differences (but not all, see below) due to Trim were clearly pre-existing differences in species composition caused by patchy species distributions and their influence on the NMS results. We interpret the significant effect of Debris treatments on Axis 3 in the same way, particularly because there was no interaction with Time (Table 2) that would suggest an effect of the treatments following the pre-manipulation period.

NMS ordination of a species matrix reduced to the 40 most common species did not resolve these issues in the analysis (RHEPOR remained in this analysis because it was relatively common, CORSUL did not). In fact, the analysis of more common species was remarkably similar to that reported here, except that larger portions of variance were explained by the three axes (as would be expected because the isolated occurrences of rare species produce "noise" in the analysis; McCune and Grace, 2002). Thus, the patterns, as untidy as they are, are robust with respect to the inclusion of rare species and we proceeded with the full species matrix so that the methods and results are consistent with changes in species richness described above.

What is most clear is that the changes in species composition over time, on average, proceeded in opposite directions in the Trim vs. No trim treatments (Fig. 5), supported by significant Trim $\times$ time interactions along both Axes 1 and 2 (Table 1 ). The central portion of the ordination species space was dominated by common non-pioneer species such as $D$. excelsa, $M$. bidentata, and $S$. berteroana in the upper right hand center portion and pioneers such as C. schreberiana, P. berteroana, Alchorneopsis floribunda, and Schefflera morototoni in the lower left center. This is the dominant vector for the trajectory of change over time and indicates that the Trim treatments were gaining pioneer species over time and the 

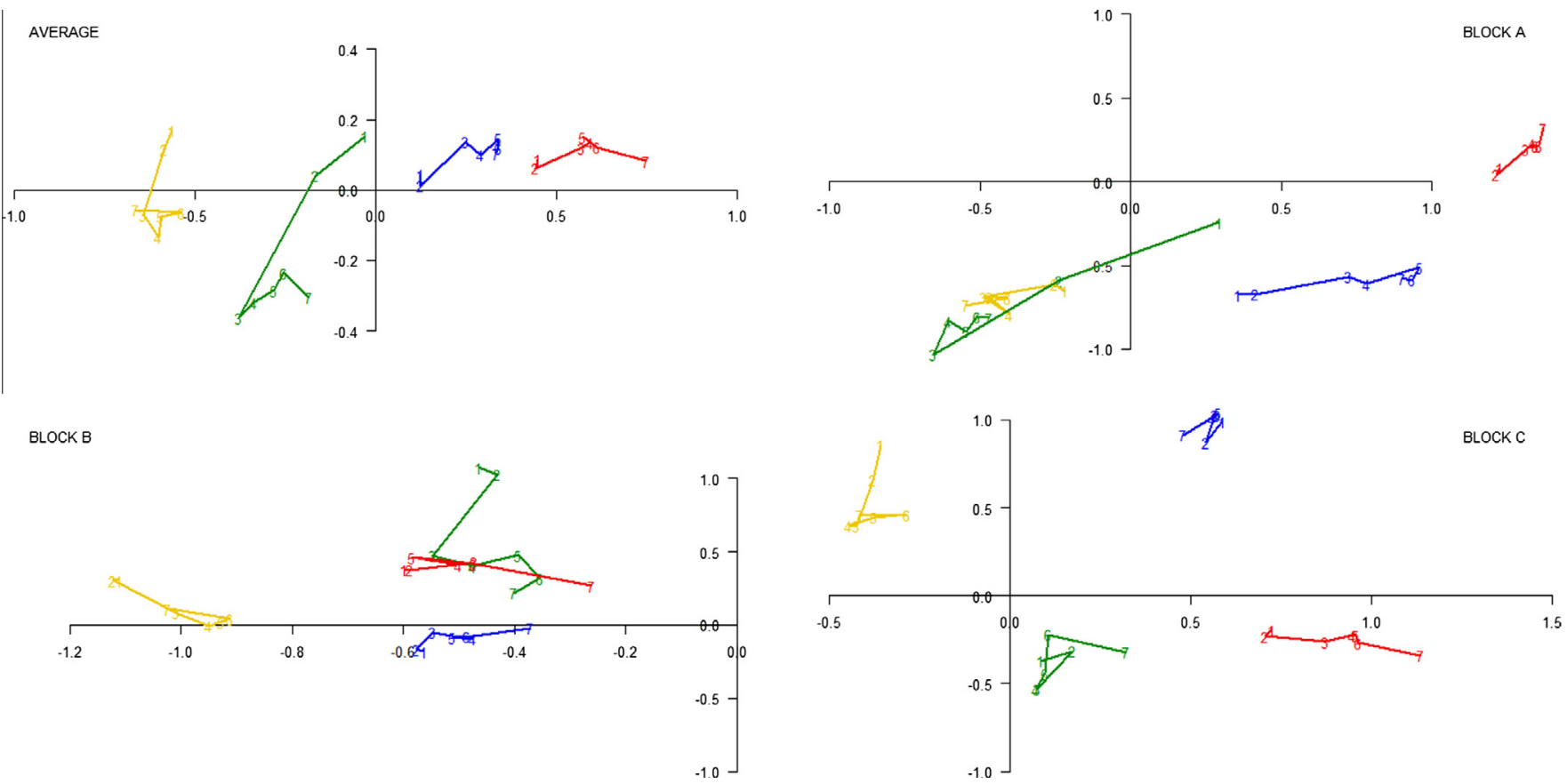

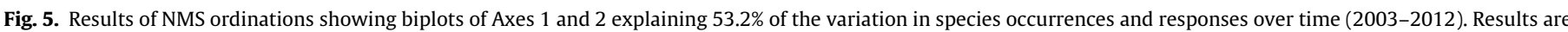

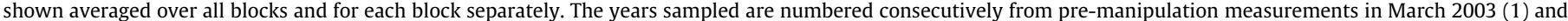

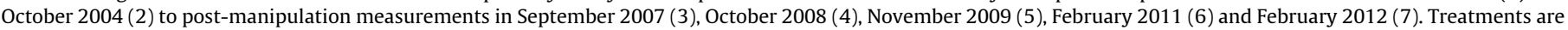

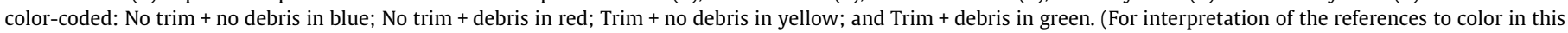
figure legend, the reader is referred to the web version of this article.)

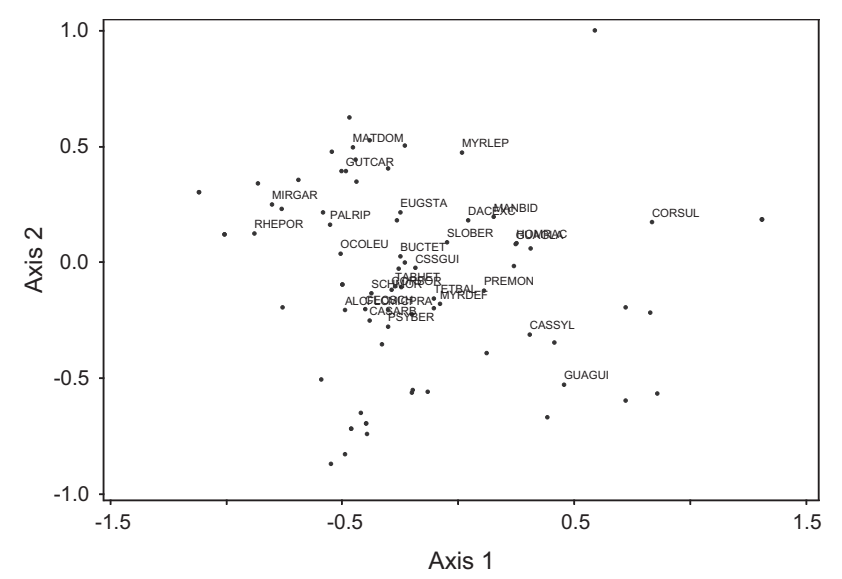

Fig. 6. Locations of each of the 80 species in the ordination space depicted in Fig. 5. Six letter species codes (Table 3 ) are shown for some common species and, for illustrative purposes, one rare species (CORSUL).

No trim plots were losing these species over time in favor of non-pioneer species.

\section{Discussion}

This experimental study of the responses of woody vegetation to the two primary effects of severe hurricane disturbance, canopy opening and debris deposition, emphasizes the long-held view that canopy opening is a critical effect of wind disturbance on subsequent forest dynamics (Everham and Brokaw, 1996; Angulo-Sandoval et al., 2004; Lugo, 2008; Barker Plotkin et al., 2013). While debris deposited during a hurricane may kill much of the existing seedling bank (You and Petty, 1991; Walker et al., 2003; Shiels et al., 2010) and contribute to small increases in tree basal area growth (Shiels et al., 2010), these effects are either very transitory, usually lasting no more than 2 years, or they exhibit small magnitude impacts on woody vegetation dynamics compared to canopy opening. The pulse in recruitment of stems due primarily to the recruitment of pioneer species (Shiels et al., 2010), which recruit heavily after hurricane disturbance at our site (Zimmerman et al., 2010), is also a transient phenomenon, one lasting at most 2.5 years post-disturbance. Yet, this recruitment pulse sets in motion changes in the forest community lasting 50 or more years (Crow, 1980; Lugo et al., 2000), depending on subsequent hurricane occurrence. Pioneer species rapidly increase in abundance in the community then slowly become lost due to thinning as the forest canopy fills. A few pioneers reach adult status in the canopy, only to be lost over time as they are replaced by longlived, slow-growing species (Lugo et al., 2000). Our study not only captures the initial response to canopy opening but, because the No trim plots were still responding to disturbance caused by Hurricane Georges before our study began, we can also trace structural and community responses to the most recent natural disturbance 14 years before our study began.

In this study we focused on forest structure and community dynamics through seven years post-treatment, augmenting the observations of Shiels et al. (2010) who ended their study at ca.3.5 years post-treatment. This allowed us to confirm the transitory nature of the pulse of recruitment caused by canopy opening, further investigate apparent positive effects of debris deposition on basal area accumulation, and investigate long-term patterns of sapling recruitment and tree mortality. As already mentioned, the prominent recruitment of saplings into the Trim treatments appeared to end after the 2007 measurements, emphasizing the narrow window of opportunity for new tree establishment caused by the pulse then rapid decline in light availability at the forest floor (Angulo-Sandoval et al., 2004; Shiels et al., 2010; Shiels and González, 2014). Following this began a period of self-thinning as the new recruits began to die due to shading from the rapidly closing forest canopy. 
Table 3

Species mentioned in text and figures, indicating family and codes used for Fig. 6.

\begin{tabular}{|c|c|c|}
\hline Species & Family & Species code \\
\hline \multicolumn{3}{|l|}{ Pioneer } \\
\hline Alchorneopsis floribunda Sw. & Euphorbiaceae & ALCFLO \\
\hline Cecropia schreberiana Miq. & Moraceae & $\mathrm{CECSCH}$ \\
\hline Miconia prasina (Sw.) DC. & Melastomataceae & MICPRA \\
\hline Palicourea riparia Benth. & Rubiaceae & PALRIP \\
\hline Psychotria berteroana DC. & Rubiaceae & PSYBER \\
\hline Schefflera morototoni (Aubl.) Decne. \& Planch. & Araliaceae & SCHMOR \\
\hline \multicolumn{3}{|l|}{ Non-pioneer } \\
\hline Buchenavia tetraphylla (Aubl.) R.A. Howard & Boraginaceae & BUCTET \\
\hline Casearia arborea (L.C. Rich.) Urban & Flacourtiaceae & CASARB \\
\hline Casearia sylvestris Sw. & Salicaceae & CASSYL \\
\hline Cordia borinquensis Urban & Boraginaceae & CORBOR \\
\hline Cordia sulcata DC. & Boraginaceae & CORSUL \\
\hline Cassipourea guianensisAubl. & Rhizophoraceae & CSSGUI \\
\hline Dacryodes excelsa Vahl & Burseraceae & DACEXC \\
\hline Eugenia stahlii (Kiaersk.) Krug \& Urb. & Myrtaceae & EUGSTA \\
\hline Guatteria caribaea Urban & Annonaceae & GUTCAR \\
\hline Guarea glabra Vahl & Meliaceae & GUAGLA \\
\hline Hirtella rugosa Pers. & Chrysobalanaceae & HIRRUG \\
\hline Homalium racemosum Jacq. & Flacourtiaceae & HOMRAC \\
\hline Manilkara bidentata (A. DC.) A. Chev. & Sapotaceae & MANBID \\
\hline Matayba domingensis (DC.) Radlk. & Sapindaceae & MATDOM \\
\hline Micropholis garciniifolia Pierre & Sapotaceae & MIRGAR \\
\hline Myrcia deflexa (Poir.) DC. & Myrtaceae & MYRDEF \\
\hline Myrcia leptoclada DC. & Myrtaceae & MYRLEP \\
\hline Ocotea leucoxylon (Sw.) Laness. & Lauraceae & OCOLEU \\
\hline Prestoea acuminata (Wiild.) H.E. Moore var. montana (Graham) Henderson and Galeano & Arecaceae & PREMON \\
\hline Rheedia portoricensis Urban & Guttiferae & RHEPOR \\
\hline Sloanea berteroana Choisy & Elaeocarpaceae & SLOBER \\
\hline Tabebuia heterophylla (DC.) Britton & Bignoniaceae & TABHET \\
\hline Tetragastris balsamifera (Sw.) Kuntze & Burseraceae & TETBAL \\
\hline
\end{tabular}

Shiels et al. (2010) provided initial results indicating that additions of hurricane debris to both trimmed and closed canopy plots caused a significant increase in basal area increment. They attributed this increase, which occurred ca. 2.3-3.5 years post-treatment, to either a fertilization effect, the benefits of increased soil moisture, or other unmeasured effects of decomposing debris on tree growth. Understanding the long-term patterns in BA growth, studied here, was complicated by a rapid loss of BA from 2007 to 2009 in a single plot, which gave the appearance of an overall loss of BA in the Trim + no debris treatment. This was caused by the death of several trees in this single plot, a pattern that cannot be attributed to the treatment effects because it was isolated within a single plot. The long-term pattern, therefore, is that debris addition likely had a positive effect on BA growth, as concluded by Shiels et al. (2010), while trim treatment had no discernible negative effects on BA increment.

We also wanted to more carefully investigate long-term patterns of morality caused by treatments in the CTE in light of reports of delayed mortality of trees reported by Walker (1995). Much of the mortality of trees up to 3.3 years post-hurricane in Walker's (1995) study was due to the slow death of trees that had been tipped-up during the hurricane, exposing all or part of the root ball. This aspect of hurricane disturbance was not examined in this study, but the stress of severe pruning used to simulate the loss of branches in a hurricane might be expected to cause increased mortality, especially where debris removal might deny trees access to moisture or nutrients supporting their survival. We found no evidence of this in trees $\geqslant 10 \mathrm{~cm}$ DBH. At the level of detection in this study, therefore, we cannot ascribe any effect of the experimental treatments on plant mortality, other than the self-thinning of newly recruited pioneers in the Trim treatments.

We took advantage of the long-term nature of the observations of the tree community in the CTE to determine whether long-term changes in species diversity, measured here using species richness, in the experimental treatments conform to predictions of the
Intermediate Disturbance Hypothesis (Connell, 1978; Doyle, 1981). IDH predicts that diversity of forest undergoing succession, either throughout the entire stand or in local patches (the "within" vs. "between patch" models of IDH; Sheil and Burslem, 2004), will exhibit a hump-shaped change through time or space (Connell, 1978; Molino and Sabatier, 2001). Any disturbance of the canopy should result in an increase in species richness owing to the recruitment of pioneer species amongst the surviving non-pioneer species (Shiels et al., 2010). We tested this in the CTE by taking plots with the canopy trimmed as recently disturbed areas and comparing them with No trim plots that were last disturbed during Hurricane Georges in 1998. We found that the results depended strongly upon whether species richness was corrected for stem density or not (discussed below) and debris treatment, but for $\mathrm{S}$ there appeared to be a peak in species diversity 3-5 years after canopy disturbance. Clearly, much of the impact on species richness in our study was due to changes in stem density over time, which increased temporarily in the trim treatments and appeared to decline steadily with time in the intact canopy treatments, in parallel with changes in the density of stems in the smallest size classes. Once the impact of stem density was removed, changes in species diversity were muted and patterns disappeared or changed. For example, the loss of species in the No trim + no debris plots almost disappeared completely, and the small peak in diversity in the Trim + no debris treatment of about 1 species per 50 stems became delayed, peaking in early 2011 rather than in 2007.

We calculated diversity in these two ways because of the need to separate the effect of stem density on species richness per unit area (i.e., species density) from changes in richness per number of stems (Hubbell et al., 1999). Rarefaction is the appropriate method to make this correction (Chazdon et al., 1999; Gotelli and Colwell, 2001 ) and we corrected our sampling to 50 stems to make comparisons amongst plots and sampling times. It is not clear why correcting species diversity for stem density is the most appropriate manner to test IDH (Chazdon et al., 1999; Hubbell et al., 1999; 
Brokaw and Busing 2000; Molino and Sabatier, 2001; Sheil and Burslem, 2004) except to account for the eventual thinning process, which has been shown to promote greater diversity in tropical forest around the world (Wills et al., 2006). Therefore, our approach, in effect, brackets the possible outcomes and suggests a small but important role of disturbance in maintaining forest diversity (Bongers et al., 2009). Both density and the scale at which diversity is measured affect the subsequent diversity conclusions (Chazdon et al., 1999). Our plot-based study reflects the measured gap sizes produced during hurricanes (Brokaw and Grear, 1991; Zimmerman et al., 2010), and our experimental measures reveal the limited power of disturbance in contributing to forest diversity at this scale (Vandermeer et al., 2000; Bongers et al., 2009).

The ordination studies of changes in species composition in space and time corroborate the limited effects of canopy opening on species richness. The analyses revealed a guild of pioneers, including $C$. schreberiana and $P$. berteroana, identified as key pioneer species by Shiels et al. (2010), which responded to the trim treatments and which were being lost at a low rate from the plots where the canopy was intact. This later aspect reveals the longterm impact of Hurricane Georges (1998), the last severe storm to strike our site, on the background dynamics of the forest mosaic, and contributes to our understanding of the role of hurricanes in regulating long-term (i.e., decadal) variation in the species composition of hurricane-driven forests (Crow, 1980; Lugo et al., 2000). These results are also consistent with our understanding of the role of hurricanes in maintaining species with contrasting life histories demonstrating resistance versus resilience to hurricane disturbance (Zimmerman et al., 1994; Boucher et al., 1994; Uriarte et al., 2012). As monitoring of the CTE proceeds, we will be able to determine to what degree pioneer species regulate successional processes of the forest. The emerging view is that pioneers do not have a strong negative influence on the dynamics of the remaining community (Vandermeer et al., 2000; Uriarte et al., 2010; Barker Plotkin et al., 2013) but rather function as ruderals (Grime, 1977) that are able to take advantage of the brief period of high resource levels caused by disturbance (Pacala and Rees, 1998) to flourish and to sometimes reach the forest canopy.

Our results reveal strongly the difficulties of performing an experimental test of hurricane disturbance effects in a heterogeneous forest environment. Beyond the logistical difficulties of removing and depositing large amounts of trimmed material in a timely manner and the limited size of the canopy openings (Shiels et al., 2010), we also encountered problems of limited replication and high background variation that sometimes produced pretreatment differences that made interpretation difficult. One way to correct for this is to adjust subsequent changes in the studied variables to their initial values, as done by Willig et al. (2014) and Barker Plotkin et al. (2013). Our approach, given two premanipulation samples spanning 1.5 years, was to focus on interactions of treatments with time and not the main effects of the treatments as a key result, reasoning that this would provide a robust detection of any responses to the experimental treatments. In any case, stem density and mortality patterns and the ordination results underscore the extreme spatial variability of demographic characteristics and species composition in the forest mosaic and provides context for understanding the moderate impact of canopy opening on species richness and species composition patterns. Even though we carefully selected locations for the CTE according to similar land use history and topography (Foster et al., 1999; Thompson et al., 2002), the ordination results emphasize the strong role of chance and history in determining localized patterns of species composition (Brokaw and Busing, 2000). Integrating two-decades of change in community composition over large spatial scales in the 16 ha Luquillo Forest Dynamics Plot (which lies adjacent to the CTE blocks; Shiels and González, 2014), produced a clear community response that was used to measure the grain of the disturbance (Zimmerman et al., 2010). Moreover, quantitative studies from the LFDP clearly demonstrate an ability to detect unique life history characteristics of species responding to hurricane disturbance (Zimmerman et al., 1994; Uriarte et al., 2010; 2012). But, to experimentally test hurricane effects at anywhere near the scale of the LFDP would be logistically difficult (if not impossible) and, in the end, we chose to balance the trade-off between scale of treatment and the difficulties of interpreting an unreplicated experiment (Barker Plotkin et al., 2013).

The forest responses to the CTE treatments detailed here also provide an important context for interpreting the other studies in this special issue, as many of the ecosystem and responses of other organisms are regulated by or integrate the woody plant response. It is important to note that the woody plant community response recorded within the trim treatments in the CTE mirror the community responses to natural hurricane disturbance monitored elsewhere at our site (e.g., Walker et al., 1991, 1996, Scatena et al., 1996; Zimmerman et al., 2010), difficulties of scale, replication, and background variability aside. Therefore, one can have confidence that interpretations of the responses of other functional variables and organismal groups to canopy trimming are similar to that of natural hurricanes (McDowell, 2014). Fern responses (Sharpe and Shiels, 2014) were similar to that for woody vegetation (Shiels et al. 2010; this study), by showing that debris deposition could cause high mortality of buried plants, that canopy opening caused an increased abundance of pioneer species, and by revealing the strong resilience of the dominant species to hurricane disturbance. Silver et al. (2014) report that trim treatments influenced leaf litter quantity (reduced for 2.5 years) and quality (increased $\mathrm{N}$ and $\mathrm{P}$ concentrations) but found no influence of debris additions on these variables. The increased nutrient concentrations in litter likely reflect, in part, the high recruitment of pioneers into the recovering forest canopy and the high nutrient content of their litterfall. Thus, even though it is not clear which pioneer species might have responded to the trim treatments, it is clear that as a guild of species they strongly influence this key ecosystem variable, ensuring high levels of nutrient return to the forest floor during the period when the forest canopy is recovering (Scatena et al., 1996). In this way pioneers may facilitate establishment and growth of late successional plants (Callaway and Walker 1997) as they clearly do on landslide scars in the LEF (Walker et al. 2010). Silver et al. (2014) detected no effect of debris deposition on litter production such that the only impact of hurricane debris on aboveground forest productivity was via the positive effect on basal area shown in this study.

\section{Conclusions}

We find that four additional years of observation allows us to clarify some of the experimental hurricane effects of the CTE on tree community structure and dynamics (Shiels et al., 2010). We find support for the notion that much of the dynamics of forest subjected to hurricane effects are to be found primarily in the smallest stem classes (Zimmerman et al., 2010), which include pioneer species able to take greatest advantage of the canopy opening caused by hurricanes (Angulo-Sandoval et al., 2004). Even though some have found that there is delayed mortality due to hurricanes (Walker, 1995), this was due to damage that involved the main stem; the mortality of large $(\geqslant 10 \mathrm{~cm} \mathrm{DBH})$ trees were unaffected by our treatments. Tree basal area increases appeared to be positively influenced by the presence of debris, which would lead one to expect that debris removal following canopy disturbance might stress trees and cause increased mortality; however, such a pattern was not observed. Finally, in testing IDH, tree species 
diversity in this tropical forest increased somewhat following canopy disturbance, but this pattern largely disappeared when corrected for stem density. Patterns of species composition were highly variable due to background variation in composition, but we were able to clearly identify the signature of pioneer species recruiting into the trim plots following canopy trimming. Beyond the transient negative effects of debris deposition on the seedling layer, described by Shiels et al. (2010), we are only able to substantiate a small positive effect of debris deposition on basal area increment. Thus, the dominant effect of the experimental disturbance effects on the woody vegetation in the CTE appears to be canopy opening and not debris deposition.

\section{Acknowledgements}

This project would not have been possible without the $>50$ volunteers and staff that assisted with the physically demanding task of canopy detritus collection and redistribution. We thank the team of professional aborists from Econet S.A, headed by William González. We thank the following people for assistance with plant measurements: Pedro Anglada Cordero, María Aponte Pagán, Diana García-Montiel, Jennifer Holm, David Horton, Paola Olaya, Jeff Pacelli. An original version of this manuscript was greatly improved by comments provided by two anonymous reviewers. This research was funded by grants DEB-0218039 and DEB-0620910 from the National Science Foundation to the Institute for Tropical Forestry, USDA Forest Service, as part of the Luquillo Long-Term Ecological Research Program. Additional direct support was provided by the University of Puerto Rico and the USDA Forest Service.

\section{References}

Angulo-Sandoval, P., Fernández-Marín, H., Zimmerman, J., Aide, T., 2004. Changes in patterns of understory leaf phenology and herbivory following hurricane damage. Biotropica 36, 60-67.

Axelrod, F., 2011. A Systemic Vademecum to the Vascular Plants of Puerto Rico. Botanical Research Institute of Texas, Fort Worth.

Barker Plotkin, A., Foster, D., Carson, J., Magill, A., 2013. Survivors, not invaders, control forest development following simulated hurricane. Ecology 94, 414423.

Bellingham, P., Tanner, E., Healey, J., 1995. Damage and responsiveness of Jamaican montane tree species after disturbance by a hurricane. Ecology 76, 2562-2580.

Bongers, F., Poorter, L., Hawthorne, W.D., Sheil, D., 2009. The intermediate disturbance hypothesis applies to tropical forests, but disturbance contributes little to tree diversity. Ecol. Lett. 12, 798-805.

Boucher, D.H., Vandermeer, J.H., Mallona, M.A., Zamora, N., Perfecto, I., 1994. Resistance and resilience in a directly regenerating rainforest: Nicaraguan trees of the Vochysiaceae after Hurricane Joan. For. Ecol. Manage. 68, 127-136.

Brokaw, N.V., Grear, J.S., 1991. Forest structure before and after Hurricane Hugo at three elevations in the Luquillo Mountains, Puerto Rico. Biotropica 23, 386-392.

Brokaw, N., Busing, R.T., 2000. Niche versus chance and tree diversity in forest gaps. Trends Ecol. Evol. 15, 183-188.

Brokaw, N., Fraver, S., Grear, J.S., Thompson, J., Zimmerman, J.K., Waide, R.B., Everham III, E.M., Hubbell, S.P., Foster, R.B., 2004. Disturbance and canopy structure in two tropical forests. In: Losos, E., Leigh, E.G., Jr. (Eds.), Tropical Forest Diversity and Dynamism. University of Chicago Press, Chicago, USA, pp. 177-194.

Burslem, D.F.R.P., Whitmore, T.C., 1999. Species diversity, susceptibility to disturbance and tree population dynamics in tropical rain forest. J. Veg. Sci. 10, 767-776.

Callaway, R.M., Walker, L.R., 1997. Competition and facilitation: a synthetic approach to interactions in plant communities. Ecology 78, 1958-1965.

Carlton, G., Bazzaz, F., 1998. Regeneration of three sympatric birch species on experimental hurricane blowdown microsites. Ecol. Monogr. 68, 99-120.

Chazdon, R.L., Colwell, R.K., Denslow, J.S., 1999. Tropical tree richness and resourcebased niches. Science 285, 1459.

Clarke, K.R., 1993. Non-parametric multivariate analyses of changes in community structure. Aust. J. Ecol. 18, 117-143.

Condit, R., 1998. Tropical Forest Census Plots: Methods and Results from Barro Colorado Island, Panama and a Comparison with Other Plots. Springer-Verlag, Berlin.

Connell, J.H., 1978. Diversity in tropical rain forests and coral reefs. Science 199, $1302-1310$.

Cooper-Ellis, S., Foster, D.R., Carlton, G., Lezberg, A., 1999. Forest response to catastrophic wind: results from an experimental hurricane. Ecology 80, 26832696.
Crow, T.R., 1980. A rainforest chronicle: a 30-year record of change in structure and composition at El Verde, Puerto Rico. Biotropica 12, 42-55.

Doyle, T.W., 1981. The role of disturbance in the gap dynamics of a montane rain forest: an application of a tropical forest succession model. In: West, D.C., Shugart, H.H., Botkin, D.B. (Eds.), Forest Succession: Concepts and Application. Springer, New York, pp. 56-73.

Everham, E.M., Brokaw, N.V., 1996. Forest damage and recovery from catastrophic wind. Bot. Rev. 62, 113-185.

Ewel, J.J., Whitmore, J.L., 1973. Ecological life zones of Puerto Rico and US Virgin Islands. United States Forest Service Research Paper. ITF-18. Institute of Tropical Forestry, Rio Piedras, Puerto Rico.

Foster, D., Fluet, M., Boose, E., 1999. Human or natural disturbance: landscape-scale dynamics of the tropical forests of Puerto Rico. Ecol. Appl. 9, 555-572.

Fox, J.W., 2013. The intermediate disturbance hypothesis should be abandoned, Trends Ecol. Evol. 28, 86-92.

Gotelli, N.J., Colwell, R.K., 2001. Quantifying biodiversity: procedures and pitfalls in the measurement and comparison of species richness. Ecol. Lett. 4, 379391.

Grime, J.P., 1977. Evidence for the existence of three primary strategies in plants and their relevance to ecological and evolutionary theory. Am. Nat. 111, 11691194.

Hubbell, S.P., Foster, R.B., O’Brien, S.T., Harms, K., Condit, R., Wechsler, B., Wright, S.J., De Lao, S.L., 1999. Light-gap disturbances, recruitment limitation, and tree diversity in a neotropical forest. Science 283, 554-557.

Imbert, D., Portecop, J., 2008. Hurricane disturbance and forest resilience: assessing structural vs. functional changes in a Caribbean dry forest. For. Ecol. Manage. 255, 3494-3501.

Lawrence, M.M.A., 2013. Package 'ez': Easy analysis and Visualization of Factorial Experiments. R Package version 4.2-2.

Lodge, D.J., Scatena, F.N., Asbury, C.E., Sánchez, M.J., 1991. Fine litterfall and related nutrient inputs resulting from Hurricane Hugo in subtropical wet and lower montane rain forests of Puerto Rico. Biotropica 23, 364-372.

Lugo, A., 2008. Visible and invisible effects of hurricanes on forest ecosystems: an international review. Aust. Ecol. 33, 368-398.

Lugo, A., Figueroa Colón, J., Scatena, F., 2000. The Caribbean. In: Barbour, M.G., Billings, W.D. (Eds.), North American Terrestrial Vegetation, second ed. Cambridge University Press, UK, pp. 594-622.

McCune, B., Grace, J.B., 2002. Analysis of Ecological Communities. MJM Software Design, Gleneden Beach, OR, USA.

McCune, B., Mefford, M.J., 2011. PC-ORD. Multivariate Analysis of Ecological Data, version 6.08. MjM Software.

McDowell, W.H., Liptzin, D., 2014. Linking soils and streams: response of soil solution chemistry to simulated hurricane disturbance mirrors stream chemistry following a severe hurricane. For. Ecol. Manage. 332, 56-63.

McGroddy, M., Lawrence, D., Schneider, L., Rogan, J., Zager, I., Schmook, B., 2013. Damage patterns after Hurricane Dean in the southern Yucatán: has human activity resulted in more resilient forests? For. Ecol. Manage. 310, 812-820.

Miller, A.D., Chesson, P., 2009. Coexistence in disturbance-prone communities: How a resistance-resilience trade-off generates coexistence via the storage effect. Am. Nat. 173, E30-E43.

Miller, A.D., Roxburgh, S.H., Shea, K., 2011. How frequency and intensity shape diversity-disturbance relationships. Proc. Natl. Acad. Sci. 108, 5643-5648.

Molino, J.F., Sabatier, D., 2001. Tree diversity in tropical rain forests: a validation of the intermediate disturbance hypothesis. Science 294, 1702-1704.

Oksanen, J., Blanchet, F.G., Kindt, R., Legendre, P., Minchin, P.R., O'Hara, R., Simpson, G.L., Oksanen, M.J., Suggests, M., 2013. Package ‘vegan': Community Ecology Package. R Package version 2.0-10.

Pacala, S.W., Rees, M., 1998. Models suggesting field experiments to test two hypotheses explaining successional diversity. Am. Nat. 152, 729-737.

R Development Core Team, 2013. R: A Language and Environment for Statistical Computing. The R Foundation for Statistical Computing, Vienna.

Richardson, B.A., Richardson, M.J., González, G., Shiels, A.B., Srivastava, D.S., 2010. A canopy trimming experiment in Puerto Rico: the response of litter invertebrate communities to canopy loss and debris deposition in a tropical forest subject to hurricanes. Ecosystems 13, 286-301.

Scatena, F., Moya, S., Estrada, C., Chinea, J., 1996. The first five years in the reorganization of aboveground biomass and nutrient use following Hurricane Hugo in the Bisley Experimental Watersheds, Luquillo Experimental Forest, Puerto Rico. Biotropica 28, 424-440.

Sharpe, J., Shiels, A.B., 2014. Understory fern community structure, growth and spore production responses to a large-scale hurricane experiment in a Puerto Rico rainforest. For. Ecol. Manage. 332, 75-86.

Sheil, D., Burslem, D.F., 2004. Disturbing hypotheses in tropical forests. Trends Ecol. Evol. 18, 18-26.

Sheil, D. Burslem, D.F.R.P., 2013. Defining and defending Connell's intermediate disturbance hypothesis: a response to Fox. Trends Ecol. Evol. 28, $571-572$.

Shiels, A.B., González, G., 2014. Understanding the key mechanisms to tropical forest responses to canopy loss and biomass deposition from experimental hurricane effects. For. Ecol. Manage. 332, 1-10.

Shiels, A.B., Zimmerman, J.K., García-Montiel, D.C., Jonckheere, I., Holm, J., Horton, D., Brokaw, N., 2010. Plant responses to simulated hurricane impacts in a subtropical wet forest, Puerto Rico. J. Ecol. 98, 659-673.

Silver, W.L., Hall, S.J., González, G., 2014. Differential effects of canopy trimming and litter deposition on litterfall and nutrient dynamics in a wet subtropical forest. For. Ecol. Manage. 332, 47-55. 
Soil Survey Staff, 1995. Order 1 Soil Surveys of Luquillo Long-Term Ecological Research Grid, Puerto Rico. United States Department of Agriculture, Natural Resource Conservation Service.

Stone, G.W., Finkl, C.W. (Eds.), 1995. Impacts of Hurricane Andrew on the coastal zones of Florida and Louisiana. J. Coastal Res. 21, 1-364.

Tanner, E.V.J., Bellingham, P.J., 2006. Less diverse forest is more resistant to hurricane damage: evidence from montane rain forests in Jamaica. J. Ecol. 94, 1003-1010.

Thompson, J., Brokaw, N., Zimmerman, J.K., Waide, R.B., Everham III, E.M., Lodge, D.J., Taylor, C.M., García-Montiel, D., Fluet, M., 2002. Land use history, environment, and tree composition in a tropical forest. Ecol. Appl. 12, 13441363.

Turton, S.M., 2008. Cyclones Larry and Monica: ecological effects of two major disturbance events. Aust. Ecol. 33, 365-367.

Uriarte, M., Swenson, N., Chazdon, R., Comita, L., Kress, J., Erickson, D., ForeroMontaña, J., Zimmerman, J., Thompson, J., 2010. Trait similarity, shared ancestry, and the structure of neighborhood interactions in a subtropical wet forest: implications for community assembly. Ecol. Lett. 13, 1503-1514.

Uriarte, M., Clark, J.S., Zimmerman, J.K., Comita, L.S., Forero-Montaña, J., Thompson, J., 2012. Multidimensional trade-offs in species responses to disturbance: implications for diversity in a subtropical forest. Ecology 93, 191-205.

Vandermeer, J., de la Cerda, I.G., Boucher, D., Perfecto, I., 2000. Hurricane disturbance and tropical tree species diversity. Science 290, 788-791.

Walker, L.R., 1995. Timing of post-hurricane tree mortality in Puerto Rico. J. Trop. Ecol. 11, 315-320.

Walker, L.R., Lodge, D.J., Waide, R.B., 1991. An introduction to hurricanes in the Caribbean. Biotropica 23, 313-316.

Walker, L.R., Silver, W.L., Willig, M.R., Zimmerman, J.K. (Eds.), 1996. Responses of Caribbean ecosystems to disturbance. Biotropica 28, 414-614.

Walker, L.R., Lodge, D.J., Guzman-Grajales, S.M., Fetcher, N., 2003. Species-specific seedling responses to hurricane disturbance in a Puerto Rican rain forest. Biotropica 35, 472-485.
Walker, L.R., Landau, F.H., Velázquez, E., Shiels, A.B., Sparrow, A.D., 2010. Early successional woody plants facilitate and ferns inhibit forest development on Puerto Rican landslides. J. Ecol. 98, 625-635.

Webb, E.L., van de Bult, M., Faáumu, S., Webb, R.C., Tualaulelei, A., Carrasco, L.R. 2014. Factors affecting tropical tree damage and survival after catastrophic wind disturbance. Biotropica 46, 32-41.

Whitmore, T.C., Burslem, D.F.R.P., 1998. Major disturbance in tropical rainforests In: Newbery, D.M., Prins, H.H.T., Brown, N.D. (Eds.), Dynamics of Tropical Communities. Blackwell Science, Oxford, pp. 549-565.

Willig, M.R., Bloch, C.P., Presley, S.J., 2014. Experimental decoupling of canopy opening and debris addition on tropical gastropod populations and communities. For. Ecol. Manage. 332, 103-117.

Wills, C., Harms, K.E., Condit, R., King, D., Thompson, J., He, F., Muller-Landau, H.C., Ashton, P., Losos, E., Comita, L., Hubbell, S., LaFrankie, J., Bunyavejchewin, S., Dattaraja, H.S., Davies, S., Esufali, S., Foster, R., Gunatilleke, N., Gunatilleke, S., Hall, P., Itoh, A., John, R., Kiratiprayoon, S., Loo de Lao, S., Massa, M., Nath, C., Noor, M.N.S., Kassim, A.R., Sukumar, R., Suresh, H.S., Sun, I., Tan, S., Yamakura, T., Zimmerman, J., 2006. Nonrandom processes maintain diversity in tropical forests. Science 311, 527-531.

You, C., Petty, W.H., 1991. Effects of Hurricane Hugo on Manilkara bidentata, a primary tree species in the Luquillo Experimental Forest of Puerto Rico. Biotropica 23, 400-406.

Zimmerman, J.K., Everham III, E.M., Waide, R.B., Lodge, D.J., Taylor, C.M., Brokaw, N.V., 1994. Responses of tree species to hurricane winds in subtropical wet forest in Puerto Rico: implications for tropical tree life histories. J. Ecol. 23, 911 922.

Zimmerman, J.K., Wright, S.J., Calderon, O., Pagan, M.A., Paton, S., 2007. Flowering and fruiting phenologies of seasonal and aseasonal neotropical forests: the role of annual changes in irradiance. J. Trop. Ecol. 23, 231-251.

Zimmerman, J.K., Comita, L.S., Uriarte, M., Brokaw, N., Thompson, J., 2010. Patch dynamics and community metastability of a tropical forest: compound effects of natural disturbance and human land use. Landsc. Ecol. 25, 1099-1111. 